\title{
Sistem Pendukung Keputusan Penerimaan Calon Binaan Inkubator Wirausaha Menggunakan Metode Perbandingan Eksponensial
}

\section{Decision Support System Acceptance of Candidates Fostered by Entrepreneurship Incubator Using Exponential Comparison Method}

\author{
Heroe Santoso' ${ }^{1}$ Raisul Azhar ${ }^{2}$, Husain $^{3}$, Muliadi ${ }^{*}$ \\ $1,2,3,4$ Universitas Bumigora \\ heroe.santoso@universitasbumigora.ac.id ${ }^{1}$, raisulazhar@universitasbumigora.ac.id ${ }^{2}$, \\ husain@universitasbumigora.ac.id ${ }^{3}, 1510520156 @$ universitasbumigora.ac.id ${ }^{4 *}$
}

Submitted: 01 Desember 2021, Revised: 12 Desember 2021, Accepted: 28 Desember 2021

\begin{abstract}
Abstrak - Program seleksi calon tenan bertujuan untuk mendapatkan bibit calon tenan binaan inkubator wirausaha yang memiliki potensi, minat, kompetensi dasar, dan keterampilan di bidang wirausaha. Untuk mengikuti proses seleksi pembinaan di inkubator selama periode tertentu dengan tujuan melahirkan wirausaha di bidang kewirausahaan yang sukses dan berkelanjutan. Peserta berasal dari bidang usaha atau masyarakat umum terfokus pada pendampingan bagi Usaha Mikro Kecil Menengah (UMKM). Selama ini Inkubator Wirausaha Nusa Tenggara Barat (NTB) selaku pihak yang berkewenangan dalam melakukan seleksi calon binaan masih menggunakan sistem manual yang tentunya berdampak pada relatif lama dalam menentukan penerimaan calon binaan. Berdasarkan permasalahan di atas pihak Inkubator Wirausaha NTB akan beralih dari sistem manual ke Sistem Pendukung Keputusan (SPK). Metode SPK yang digunakan adalah Metode Perbandingan Eksponensial (MPE) yang merupakan salah satu metode untuk menentukan urutan prioritas alternatif keputusan dengan kriteria jamak. Metode pengembangan sistem menggunakan metode waterfall yang terdiri dari beberapa tahap antara lain : tahap analisis kebutuhan, tahap desain, tahap implementasi, tahap pengujian. Kesimpulan dari penelitian ini menghasilan Sistem Pendukung Keputusan penerimaana calon binaan inkubator wirausaha menggunakan metode perbandingan eksponensial. Berdasarkan hasil pengujian sistem dari responden menyatakan sangat setuju $97,62 \%$ dan responden setuju dengan prosentasi $2,38 \%$.
\end{abstract}

Kata kunci: tenan binaan, inkubator, UMKM

\begin{abstract}
The prospective tenant selection program aims to obtain prospective tenants fostered by entrepreneurial incubators who have potential, interests, basic competencies, and skills in the field of entrepreneurship. To follow the selection process for coaching in an incubator for a certain period with the aim of producing successful and sustainable entrepreneurs in the field of entrepreneurship. Participants come from the business sector or the general public focused on mentoring for Micro, Small and Medium Enterprises. So far, the West Nusa Tenggara (NTB) Entrepreneurial Incubator as the party with the authority in selecting fostered candidates still uses a manual system which of course has an impact on the relatively long time in determining the acceptance of fostered candidates. Based on the above problems, the NTB Entrepreneurial Incubator will switch from a manual system to a Decision Support System (DSS). The DSS method used is the Exponential Comparison Method which is one method for determining the priority order of decision alternatives with multiple criteria. The system development method uses the waterfall method which consists of several stages, including: the needs analysis stage, the design stage, the implementation stage, and the testing stage. The conclusion of this study resulted in a Decision Support System for the acceptance of prospective entrepreneurial incubators using the exponential comparison method. Based on the results of system testing, respondents stated strongly agree $97.62 \%$ and respondents agree with a percentage of $2.38 \%$.
\end{abstract}

Keywords: fostered tenants, incubators, UMKM

Jurnal Bumigora Information Technology (BITe)

Vol.3, No.2, Desember 2021, pp. 151-160

ISSN: $2685-4066$

DOI: $10.30812 /$ bite.v3i2.1586 


\section{Pendahuluan}

Pada era seperti sekarang ini teknologi dan informasi sangat berperan penting guna menunjang aktivitas sehari-hari, baik dalam dunia bisnis, hiburan, pendidikan, pemerintahan dan lain sebagainya. Data mentah diolah menjadi informasi dapat digunakan untuk membatu mendukung memutuskan dalam Sistem Pendukung Keputusan (SPK) mulai dari mengidentifikasi masalah, memilih data yang relevan, dan menentukan pendekatan yang digunakan dalam proses pengambilan keputusan sampai mengevaluasi pemilihan alternatif, melakukan penilaian, melakukan perubahan kriterai dan perubahan nilai bobot. Hal ini berguna untuk memudahkan pengambilan keputusan yang berkaitan dengan permasalahan penerimaan calon binaan inkubator wirausaha pada Inkubator Wirausaha Nusa Tenggara Barat (NTB).

Sumber daya manusia (SDM) berperan penting bagi keberlangsungan institusi oleh sebab itu Inkubator Wirausaha NTB dalam melakukan proses seleksi calon binaan membutuhkan calon yang benar-benar kompeten pada bidangnya masing masing. Permasalahan dalam penelitian ini adalah pada proses seleksi calon binaan inkubator bersifat subjektif belum adanya metode yang tepat dalam penerimaan calon binaan inkubator.

Tujuan utama dalam proses perekrutan calon binaan inkubator baru adalah untuk mendapatkan orang yang tepat pada penempatan yang tepat pula sehingga sesuai dengan kondisi dan kebutuhan organisasi atau perusahaan [1].

Sistem Pendukung Keputusan (SPK) merupakan suatu sistem interaktif yang membantu pengambilan sebuah keputusan melalui penggunaan data untuk memecahkan masalah yang sifatnya semi terstruktur dan tidak terstruktur [2].

Komponen Sistem Pendukung Keputusan (SPK) terdiri dari empat subsistem yang saling berhubungan yaitu [3] : 1. Subsistem Manajemen Data, 2. Subsistem Manajemen Model, 3. Subsistem Dialog (User Interface Subsystem), 4. Subsistem Manajemen Berbasis Pengetahuan (Knowledge-Based Management Subsystem)

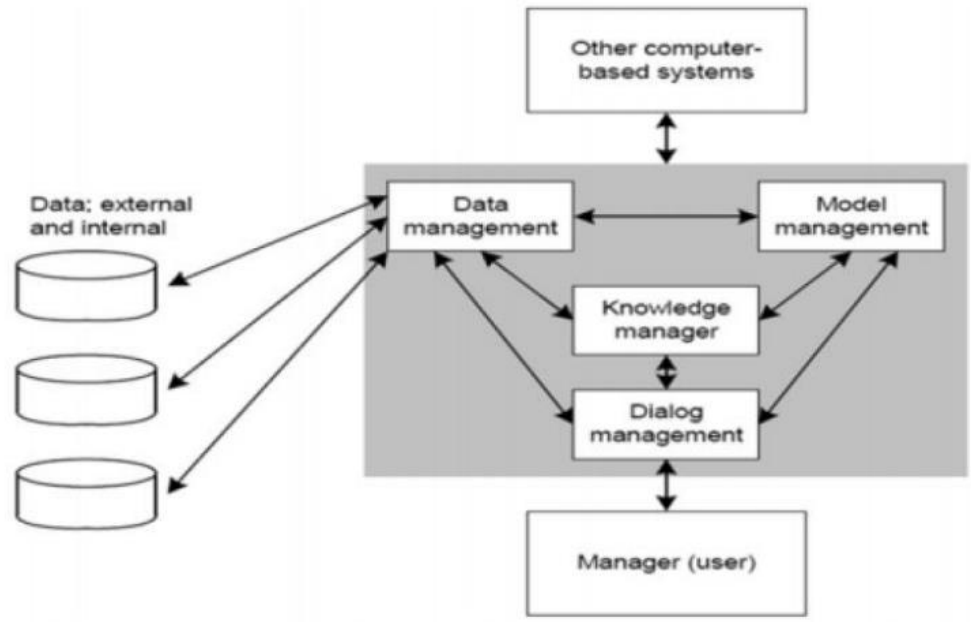

Gambar 1. Komponen sistem pendukung keputusan [2]

Metode Perbandingan Eksponensial (MPE) dapat mengurangi bias yang mungkin terjadi dalam analisis, karena nilai skor yang dihasilkan mengambarkan urutan prioritas yang menjadi besar sehingga urutan prioritas alternatif keputusan menjadi lebih nyata. Pada penelitian ini menghasilkan sistem pendukung keputusan untuk menetukan penerima beasiswa siswa berprestasi dengan kriteria prestasi, kedisiplinan, kehadiran dengan menerapkan metode MPE [4].

Metode Perbandingan Eksponensial (MPE) merupakan salah satu metode untuk menentukan urutan prioritas alternatif keputusan dengan kriteria majemuk. Teknik ini digunakan untuk membantu individu dalam pengambil keputusan ketika menggunakan rancang bangun model yang telah terdifinisi dengan baik pada tahapan proses [5]. 
Penelitian dari Tupan Tri Muryono, Irwansyah, Agus Budiyantara (2020) dengan judul Penentuan Penerimaan Pegawai Menggunakan Metode Perbandingan Eksponensial (MPE) menyampaikan: Sumber daya manusia (SDM) berperan penting bagi keberlangsungan perguruaan tinggi oleh sebab itu perguruan tinggi XYZ dalam melakukan proses seleksi pegawai membutuhkan pegawai yang benar-benar kompeten pada bidangnya masing masing. Permasalahan dalam penelitian ini adalah pada proses seleksi pegawai masih bersifat subjektif bukan berdasarkan hasil test murni dan belum adanya metode yang tepat dalam penerimaan pegawai. Tujuan dari penelitian ini adalah untuk mendapatkan pegawai yang tepat sesuai dengan kebutuhan dari perguruan tinggi. Ada lima kriteria yang akan digunakan dalam penelitian ini ialah pendidikan, pengalaman kerja, nilai psikotest, usia, dan nilai wawancara. Metode pengumpulan data yang digunakan dalam penelitian ini adalah wawancara, studi pustaka, dan observasi. Metode penelitian yang digunakan ialah Metode Perbandingan Eksponensial (MPE) dan untuk perhitungan metode MPE menggunakan bahasa pemrograman python. Hasil dari penelitian ini adalah metode MPE bisa diterapkan untuk penentuan penerimaan pegawai pada perguruan XYZ [6].

Koperasi XYZ merupakan badan usaha yang bergerak di bidang simpan pinjam, persewaan gedung, konveksi, pengadaan beras dan toko yang sangat memperhatikan kesejahteraan anggotanya. Proses penilaian keputusan persetujuan kredit pada koperasi XYZ masih kurang penilaian. Itu berdasarkan nilai rapor anggota yang meliputi jaminan, kekayaan, dan perilaku sehingga dana tidak sering tepat sasaran. Apalagi anggota koperasi sering ceroboh dalam proses pelunasan. Metode dalam penelitian ini adalah Metode Perbandingan Eksponensial. Ini metode menentukan urutan prioritas alternatif keputusan dengan kriteria. Kriteria tersebut dalam hal ini penelitian adalah: Raport, BI Checking, Tujuan Aplikasi, sumber pendapatan, pendapatan bulanan, jangka waktu angsuran, kelengkapan berkas, jaminan, status, dan jumlah yang diminta. Hasil dari menerapkan sistem ini dan menambahkan beberapa kriteria baru, kerjasama mempertimbangkan persetujuan pinjaman penilaian dalam menentukan anggota yang memenuhi syarat. Hasil pengujian fungsional dengan black-box metode menunjukkan bahwa sistem berjalan seperti yang diharapkan dan fungsi aplikasi berjalan dengan baik [7].

Metode Perbandingan Exponensial (MPE) adalah salah satu metode dari Decision Suport System (DSS) yang digunakan untuk menentukan urutan prioritas alternatif keputusan dengan kriteria jamak [8]. Dengan perhitungan secara eksponensial, perbedaan nilai antara kriteria dapat dibedakan tergantung kepada kemampuan orang yang menilai [7]. Selain itu MPE merupakan salah satu metode pengambilan keputusan yang mengkuantifikasikan pendapat seseorang atau lebih dalam skala tertentu [9]. Teknik ini digunakan untuk membantu individu pengambil keputusan untuk menggunakan rancang bangun model yang terdefinisi dengan baik pada tahapan proses. MPE akan menghasilkan nilai alternatif yang perbedaannya lebih kontras.

Ada enam kriteria yang akan digunakan dalam penelitian ini ialah: seleksi administrasi, karakter pengusaha, analisis produksi, pemasaran produksi, Sumber Daya Manusia (SDM) dan administrasi keuangan usaha. Metode yang digunakan adalah Metode Perbandingan Eksponensial (MPE) [10] yang diharapkan dapat membantu pihak Inkubator Wirausaha Nusa Tenggara Barat (NTB) dalam pengambilan keputusan dengan cepat, tepat dan bersifat lebih objektif.

\section{Metode Penelitian}

\subsection{Teknik Pengumpulan Data}

Teknik pengumpulan data merupakan langkah yang paling strategis dalam penelitian karena tujuan utama dari penelitian adalah mendapatkan data. Untuk mendapatkan data yang diperlukan. Maka digunakan metode pengumpulan data yang digunakan adalah: [5]. Pertama melakukan proses wawancara, dimana wawancara dilakukan secara langsung dengan Kepala Inkubator Wirausaha NTB. Kedua melakukan studi pustaka, dimana pengumpulan data dilakukan dengan cara meneliti sejumlah literatur atau referensi yang sekiranya dapat membantu dan mendukung kegiatan penelitian yang dilakukan. Dan yang ketiga melakukan observasi, 
yaitu dilakukan melalui pengamatan terhadap sejumlah aplikasi sistem pendukung keputusan menggunakan bahasa pemrograman PHP yang menggunakan Metode Perbandingan Eksponensial (MPE).

\subsection{Desain Sistem}

Use Case Diagram menggambarkan proses yang terjadi pada sistem. Aktor yang berinterasi langsung dengan sistem adalah Kepala Inkubator, admin dan pendaftar. Aktor pendaftar bertugas untuk memasukkan data pribadinya dan melihat hasil pengumuman pada sistem. Aktor admin bertugas untuk memasukkan data kriteria, data pendaftar dan mengolah nilai terhadap masing-masing pendaftar yang sudah diinputkan serta melakukan perhitungan menggunakan MPE dan menampilkan hasil perangkingan para pendaftar. Aktor Kepala Inkubator bertugas untuk memasukkan kriteria dan bobot kriteria. Aktor Kepala Inkubator juga bisa melihat hasil perhitungan yang telah diinputkan oleh aktor admin melalui sistem, serta mencetak hasil laporan penerimaan tenant yang diterima dan tidak diterima. Untuk lebih jelasnya dapat dilihat pada gambar 2 .

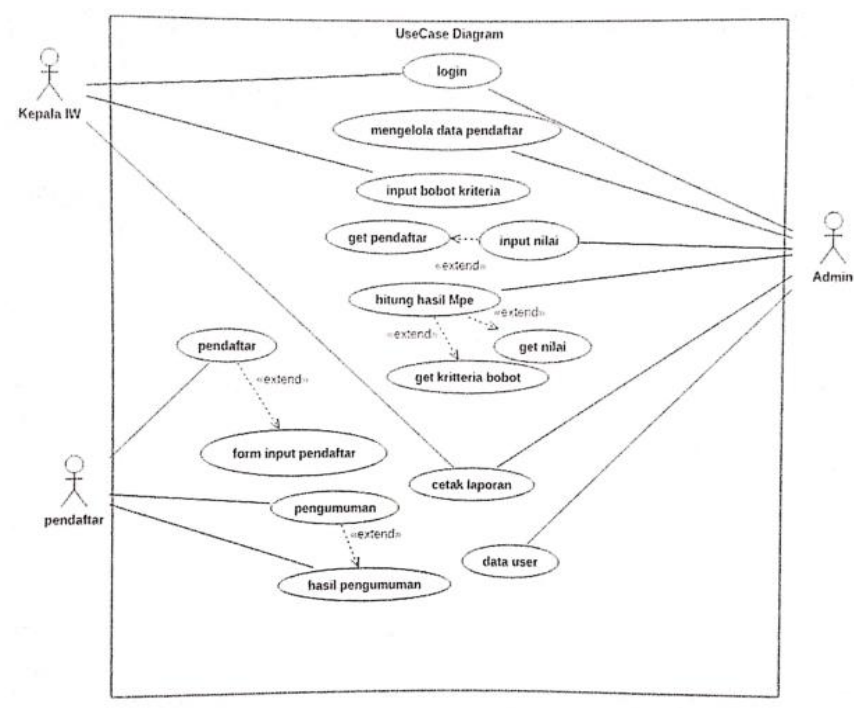

Gambar 2. Use case diagram

\subsection{Class Diagram}

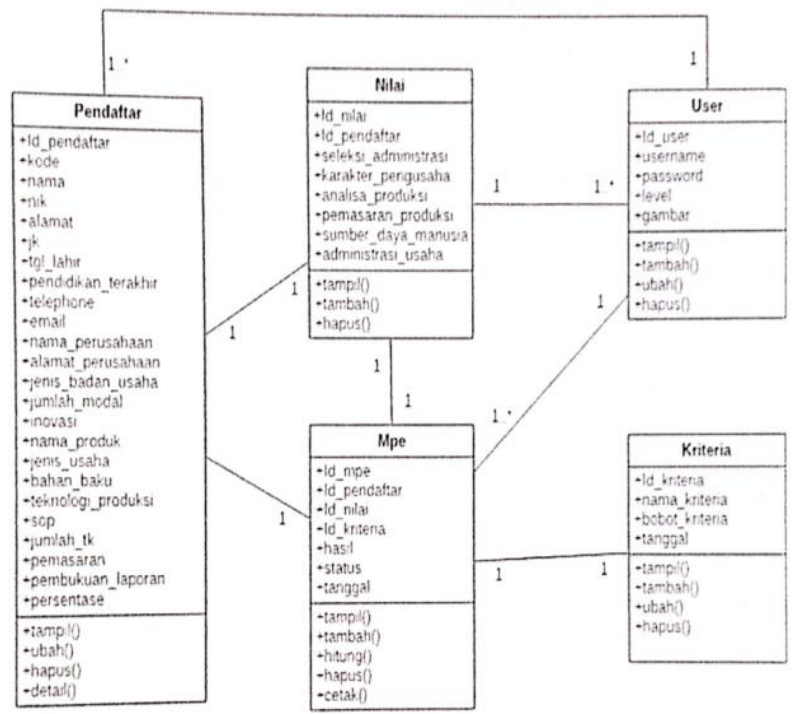

Gambar 3. Use case diagram

https://journal.universitasbumigora.ac.id/index.php/bite

ISSN: 2685-4066 


\section{Metode Penelitian}

Metode Penelitian yang digunakan yaitu Metode Perbandingan Exponensial (MPE) merupakan salah satu metode pengambilan keputusan yang mengkuantifikasikan pendapat seseorang atau lebih dalam skala tertentu. Pada prinsipnya merupakan metode skoring terhadap pilihan yang ada. Dengan perhitungan secara eksponensial, perbedaan nilai antar kriteria dapat dibedakan tergantung kepada kemampuan orang yang menilai. Langkah-langkah yang perlu dilakukan dalam pemilihan keputusan dengan MPE yaitu : Pertama menyusun alternatif keputusan. Kedua menentukan kriteria dengan bobot kriteria. Ketiga menentukan derajat kepentingan/bobot setiap kriteria keputusan dengan menggunakan skala konversi tertentu sesuai keinginan pengambil keputusan. Dan yang keempat penentuan penilaian terhadap setiap alternatif keputusan. Pemeringkatan nilai yang diperoleh dari setiap alternatif keputusan.

Perhitungan total nilai untuk setiap alternatif dalam Metode Perbandingan Exponensial (MPE) adalah sebagai berikut :

Total Nilai $\left(T N_{i}\right)=\sum_{j=1}^{m}\left(R k_{i j}\right)^{T K K_{j}}$

Keterangan :

$\mathrm{TNi}=$ Total nilai alternatif ke-i

Rkij = Derajat kepentingan relatif kriteria ke-j pada pilihan keputusan ke-i

$\mathrm{TKKj}=$ Derajat kepentingan kriteria keputusan ke-j TKKJ $>0$; bulat

$\mathrm{N}=$ Jumlah pilihan keputusan

$\mathrm{M} \quad$ = Jumlah kriteria keputusan

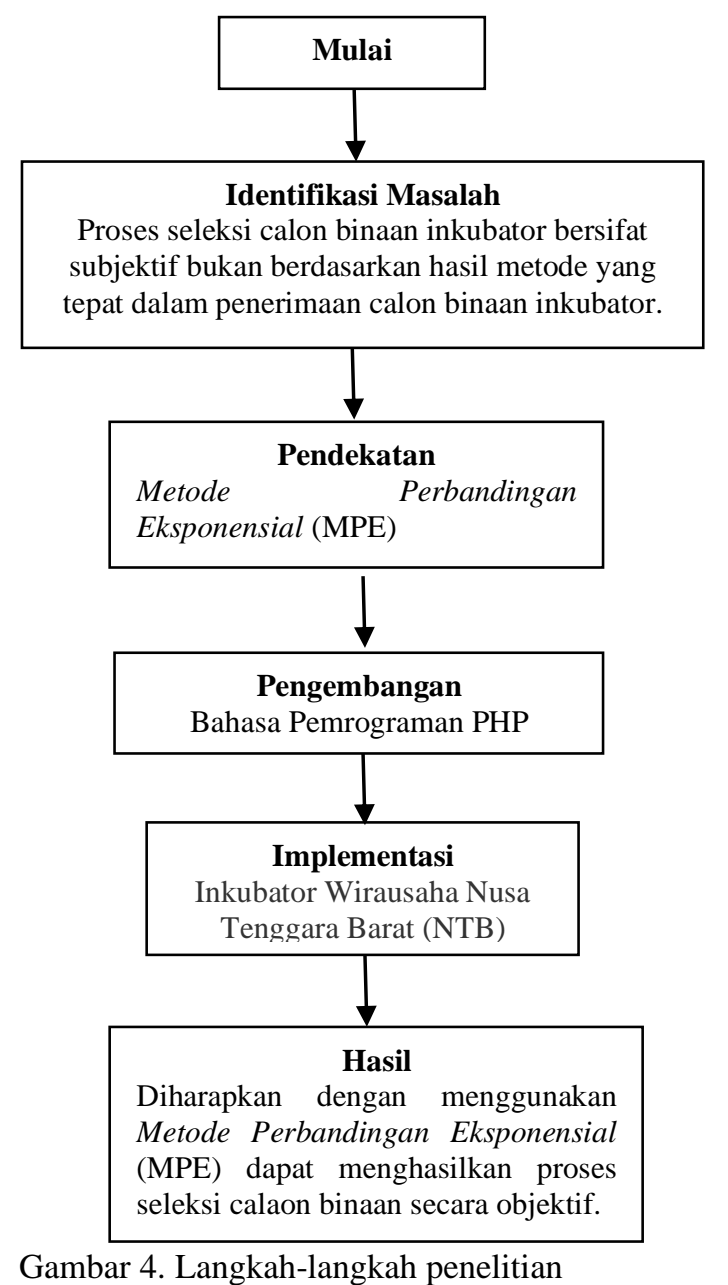

https://journal.universitasbumigora.ac.id/index.php/bite

ISSN: 2685-4066 
Pertama identifikasi masalah: permasalahan dalam penelitian ini adalah pada proses seleksi calon binaan inkubator bersifat subjektif bukan berdasarkan hasil metode yang tepat dalam penerimaan calon binaan inkubator. Yang kedua pendekatan: pada penelitian ini penulis menggunakan Metode Perbandingan Exponensial. MPE merupakan salah satu metode dari Sistem Pendukung Keputusan (SPK) yang digunakan untuk menentukan urutan prioritas alternatif keputusan dengan kriteria jamak. Yang ketiga pengembangan: pada penelitian ini penulis menggunakan bahasa pemrograman PHP. Yang keempat implementasi: Hasil dari penelitian ini akan diimplementasikan pada Inkubator Wirausaha Nusa Tenggara Barat (NTB). Yang kelima adalah Hasil: hasil dalam penelitian ini dapat menghasilkan proses seleksi inkubator secara objektif.

\section{Hasil dan Pembahasan}

\subsection{Metode Perbandingan Eksponensial}

Metode Perbandingan Exponensial (MPE) yang digunakan untuk menentukan penerimaana calon binaan inkubator wirausaha yang ada di dalam penelitian ini, dengan cara menghitung nilai hasil seleksi calon binaan yang akan dipangkatkan dengan masing masing bobot kriteria. Setelah hasil sudah dipangkatkan lalu dijumlahkan. Hasil alternatif yang terbesar akan terpilih sebagai calon binaan pada Inkubator Wirausaha Nusa Tenggara Barat (NTB) [10].

\subsection{Menyusun Alternatif Keputusan}

Alternatif yang digunakan dalam analisis perhitungan sebanyak 6 terlihat pada tabel di bawah ini.

Tabel 1. Tabel alternatif

\begin{tabular}{|c|c|c|}
\hline No. & Nama & Nama Perusahaan \\
\hline 1. & Mirase & UD. Nice Mataram \\
\hline 2. & Maisah & UD. Mardhatillah \\
\hline 3. & Amalia & UD. Cempake \\
\hline 4. & Rina & UD. Sri Tami \\
\hline 5. & L. Bagus & PT. Rizki \\
\hline 6. & Muhammad & CV. Indah \\
\hline
\end{tabular}

\subsection{Menentukan Kriteria dengan Bobot Kriteria}

Kriteria yang digunakan dalam seleksi penerimaan calon binaan (tenant) yaitu :

Tabel 2. Tabel kriteria

\begin{tabular}{clc}
\hline No. & \multicolumn{1}{c}{ Nama Kriteria } & Bobot Kriteria \\
\hline 1. & Seleksi Administrasi (C1) & 5 \\
2. & Karakter Pengusaha (C2) & 5 \\
3. & Analisis Produksi (C3) & 4 \\
4. & Pemasaran Produksi (C4) & 4 \\
5. & Sumber Daya Manusia (C5) & 5 \\
6. & Administrasi Keuangan Usaha (C6) & 5 \\
\hline
\end{tabular}




\subsection{Menentukan Tingkat Kepentingan/Bobot Kriteria}

Keterangan bobot masing-masing kriteria dan skor penilaian

Tabel 3. Tabel penilaian

\begin{tabular}{|c|c|c|c|c|}
\hline No. & Nama Kriteria & Keterangan & $\begin{array}{c}\text { Skor } \\
\text { Penilaian }\end{array}$ & $\begin{array}{c}\text { Bobot } \\
\text { Kriteria }\end{array}$ \\
\hline \multirow[t]{5}{*}{1.} & Seleksi Administrasi (C1) & Kurang Sekali & 1 & \\
\hline & & Kurang & 2 & \\
\hline & & Cukup & 3 & 5 \\
\hline & & Baik & 4 & \\
\hline & & Baik Sekali & 5 & \\
\hline \multirow[t]{5}{*}{2.} & Karakter Pengusaha (C2) & Kurang Sekali & 1 & \\
\hline & & Kurang & 2 & \\
\hline & & Cukup & 3 & 5 \\
\hline & & Baik & 4 & \\
\hline & & Baik Sekali & 5 & \\
\hline \multirow[t]{5}{*}{3.} & Analisis Produksi (C3) & Kurang Sekali & 1 & \\
\hline & & Kurang & 2 & \\
\hline & & Cukup & 3 & 4 \\
\hline & & Baik & 4 & \\
\hline & & Baik Sekali & 5 & \\
\hline \multirow[t]{5}{*}{4.} & Pemasaran Produksi (C4) & Kurang Sekali & 1 & \\
\hline & & Kurang & 2 & \\
\hline & & Cukup & 3 & 4 \\
\hline & & Baik & 4 & \\
\hline & & Baik Sekali & 5 & \\
\hline \multirow[t]{5}{*}{5.} & Sumber Daya Manusia (C5) & Kurang Sekali & 1 & \\
\hline & & Kurang & 2 & \\
\hline & & Cukup & 3 & 5 \\
\hline & & Baik & 4 & \\
\hline & & Baik Sekali & 5 & \\
\hline \multirow[t]{5}{*}{6.} & Administrasi Keuangan Usaha & Kurang Sekali & 1 & \\
\hline & (C6) & Kurang & 2 & \\
\hline & & Cukup & 3 & 5 \\
\hline & & Baik & 4 & \\
\hline & & Baik Sekali & 5 & \\
\hline
\end{tabular}

\subsection{Melakukan Penilaian Terhadap Alternatif}

Masing-masing alternatif diberikan nilai terhadap semua kriteria dan dituangkan dalam matrik keputusan.

Tabel 4. Tabel Penilaian Alternatif

\begin{tabular}{lllcccccc}
\hline \multirow{2}{*}{ No. } & \multicolumn{1}{c}{ Alternatif } & \multicolumn{7}{c}{ Kriteria } \\
\cline { 2 - 9 } & \multicolumn{1}{c}{ Nama } & \multicolumn{1}{c}{ Perusahaan } & C1 & C2 & C3 & C4 & C5 & C6 \\
\hline 1. & Mirase & UD. Nice Mataram & 5 & 5 & 4 & 5 & 4 & 5 \\
2. & Maisah & UD. Mardhatillah & 5 & 5 & 3 & 4 & 5 & 4 \\
3. & Amalia & UD. Cempake & 5 & 5 & 3 & 5 & 4 & 5 \\
4. & Rina & UD. Sri Tami & 4 & 5 & 4 & 4 & 4 & 5 \\
5. & L. Bagus & PT. Rizki & 4 & 5 & 3 & 4 & 5 & 4 \\
6. & Muhammad & CV. Indah & 5 & 5 & 5 & 4 & 4 & 5 \\
\hline
\end{tabular}

Hasil penilaian dari matrik keputusan dihitung menggunakan rumus MPE sebagai berikut :

1. Mirase (UD. Nice Mataram)

Total Nilai $=5^{\wedge} 5+5^{\wedge} 5+4^{\wedge} 4+5^{\wedge} 4+4^{\wedge} 5+5^{\wedge} 5=11280$

2. Maisah (UD. Mardhatillah)

Total Nilai $=5^{\wedge} 5+5^{\wedge} 5+3^{\wedge} 4+4^{\wedge} 4+5^{\wedge} 5+4^{\wedge} 5=10736$

3. Amalia (UD. Cempake)

Total Nilai $=5^{\wedge} 5+5^{\wedge} 5+3^{\wedge} 4+5^{\wedge} 4+4^{\wedge} 5+5^{\wedge} 5=11105$

4. Rina (UD. Sri Tami)

https://journal.universitasbumigora.ac.id/index.php/bite

ISSN: 2685-4066 
Total Nilai $=4^{\wedge} 5+5^{\wedge} 5+4^{\wedge} 4+4^{\wedge} 4+4^{\wedge} 5+5^{\wedge} 5=8810$

5. L. Bagus (PT. Rizki)

Total Nilai $=4^{\wedge} 5+5^{\wedge} 5+3^{\wedge} 4+4^{\wedge} 4+5^{\wedge} 5+4^{\wedge} 5=8635$

6. Muhammad (CV. Indah)

Total Nilai $=5^{\wedge} 5+5^{\wedge} 4+5^{\wedge} 4+4^{\wedge} 4+4^{\wedge} 5+5^{\wedge} 5=8780$

\subsection{Hasil Urutan Prioritas}

Berdasarkan hasil perhitugan menggunakan MPE pada masing-masing alternatif maka diperoleh urutan calon binaan tenant.

Tabel 5. Tabel urutan prioritas

\begin{tabular}{|c|c|c|c|c|}
\hline No. & Nama & Nama Perusahaan & Nilai & Rangking \\
\hline 1. & Mirase & UD. Nice Mataram & 11280 & 1 \\
\hline 2. & Amalia & UD. Cempake & 11105 & 2 \\
\hline 3. & Maisah & UD. Mardhatillah & 10736 & 3 \\
\hline 4. & Rina & UD. Sri Tami & 8810 & 4 \\
\hline 5. & Muhammad & CV. Indah & 8780 & 5 \\
\hline 6. & L. Bagus & PT. Rizki & 8635 & 6 \\
\hline
\end{tabular}

\subsection{Simpulan}

Kesimpulan dari tabel 5 menyatakan bahwa urutan prioritas nama Mirase UD. Nice Mataram mempunyai peluang terbesar karena mempunyai nilai besar yaitu : 11280

\section{Kesimpulan}

Berdasarkan penelitian yang telah dilakukan pada Inkubator Wirausaha Nusa Tenggara Barat (NTB), maka dapat diambil kesimpulan sebagai berikut: Metode Perbandingan Eksponensial (MPE) bisa diterapkan untuk penentuan penerimaan calon binaan inkubator wirausaha. Dan bahasa yang digunakan untuk menghitung metode Perbandingan Eksponensial (MPE) adalah bahasa pemrograman PHP. Berdasarkan tabel di atas diperoleh urutan rangking dari pertama sampai keenam yaitu : Mirase UD. Nice Mataram dengan nilai 11.280 menempati rangking pertama, Amalia UD. Cempake dengan nilai 11.105 menempati rangking kedua, Maisah UD. Mardhatillah dengan nilai 10.736 menempati rangking ketiga, Rina UD. Sri Tami dengan nilai 8.810 menempati rangking keempat, Muhammad CV. Indah dengan nilai 8.780 menempati rangking kelima dan L. Bagus PT. Rizki dengan nilai 8.635 menempati rangking keenam.

\section{Ucapan Terima Kasih}

Terima kasih peneliti ucapkan kepada pihak-pihak yang terlibat dalam penelitian ini, mahasiswa atas nama Muliadi yang ikut membantu menyiapkan software yang diperlukan guna mendukung terselesainya penelitian ini, semoga penelitian ini dapat bermanfaat untuk para pembaca dan penelitian dapat digunakan sebagai rujukan dalam penelitian-penelitian sejenis.

\section{Referensi}

[1] A. A. Rizky and I. Ramdhani, "Perancangan Sistem Informasi Perekrutan Karyawan Berbasis Web Menggunakan PHP dan MySQL DI PT. Ria Indah Mandiri," J. Manaj. Inform., vol. 9, no. 1, pp. 49-57, 2019, doi: 10.34010/jamika.v9i1.1651.

[2] S. Saefudin and S. Wahyuningsih, "Sistem Pendukung Keputusan Untuk Penilaian Kinerja Pegawai Menggunakan Metode Analytical Hierarchy Process (Ahp) Pada RSUD Serang," JSiI (Jurnal Sist. Informasi), vol. 1, no. 1, pp. 33-37, 2017, doi: 10.30656/jsii.v1i0.78.

[3] G. Muhammad Priyono Tri s, "Sistem Pendukung Keputusan Prediksi Tenaga Kerja Indonesia Dengan Pendekatan Metode Trend Moment Di Jawa Timur," J. Mhs. Fak. Sains dan Teknol., vol. 1, no. 5, 2017. 
[4] R. I. Borman and H. Fauzi, "Dalam Sistem Pendukung Keputusan Penerima Beasiswa," CESS J. Comput. Eng. Syst. Sci., vol. 3, no. 1, pp. 17-22, 2018.

[5] Y. Devianto and S. Dwiasnati, "Aplikasi Pengambilan Keputusan Indeks Kepuasaan Masyarakat Dengan Metode Perbandingan Eksponensial (MPE) Pada Unit Pelayanan Masyarakat Dengan Alat Microcontroller Sebagai Alat Bantu Survey," J. Ilm. FIFO, vol. 10, no. 1, p. 13, 2018, doi: 10.22441/fifo.v10i1.2946.

[6] T. T. Muryono, I. Irwansyah, and A. Budiyantara, "Penentuan Penerimaan Pegawai Menggunakan Metode Perbandingan Eksponensial (Mpe)," Infotech J. Technol. Inf., vol. 6, no. 2, pp. 57-62, 2020, doi: 10.37365/jti.v6i2.98.

[7] W. Setiawan, "Pemilihan Guru Terbaik, MPE, con Implementasi Metode Perbandingan Eksponensial (MPE) dalam Pemilihan Guru Terbaik di SMK XYZ," JATISI (Jurnal Tek. Inform. dan Sist. Informasi), vol. 6, no. 2, pp. 212-228, 2020, doi: 10.35957/jatisi.v6i2.216.

[8] A. Wibowo and A. S. Honggowibowo, "Lokasi Peternakan Ayam Broiler Dengan Metode Perbandingan Eksponensial Dan Naive Bayes," Compiler, vol. 3, no. 2, pp. 4957, 2014, [Online]. Available: https://media.neliti.com/media/publications/236138sistem-pendukung-keputusan-untuk-menentu-81b5ad51.pdf.

[9] A. Warseno, Y. R. W. Utami, and A. Kusumaningrum, "Sistem Pendukung Keputusan Penentuan Pemberian Pinjaman Dengan Metode Perbandingan Eksponensial (MPE) Pada Koperasi XYZ,” J. Ilm. SINUS, vol. 19, no. 1, p. 49, 2021, doi: 10.30646/sinus.v19i1.527.

[10] N. Wulandari and Chriswahyudi, "Metode Perbandingan Eksponensial (Mpe) Untuk Menentukan Supplier Dan Activity Based Costing (Abc) Untuk Menentukan Produk Yang Menguntungkan Serta Uji Hedonik Untuk Mengetahui Pengaruh Bahan Baku Dari Supplier Yang Berbeda Terhadap Organoleptik Produk Di Pt. Xyz," Jurnal.umj.ac.id/index.php/semnastek, vol. 17, no. Sistem Pengambilan Keputusan, pp. 1-13, 2018 ,

[Online].

Available:https://jurnal.umj.ac.id/index.php/semnastek/article/view/3504. 
